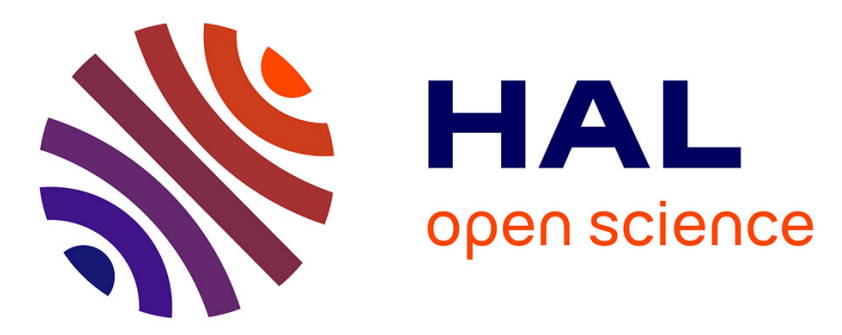

\title{
Integrating Random Shocks Into Multi-State Physics Models of Degradation Processes for Component Reliability Assessment
}

Yan-Hui Lin, Yan-Fu Li, Enrico Zio

\section{- To cite this version:}

Yan-Hui Lin, Yan-Fu Li, Enrico Zio. Integrating Random Shocks Into Multi-State Physics Models of Degradation Processes for Component Reliability Assessment. IEEE Transactions on Reliability, 2015, pp.28. 10.1109/TR.2014.2354874 . hal-01090176

\section{HAL Id: hal-01090176 https://hal.science/hal-01090176}

Submitted on 3 Dec 2014

HAL is a multi-disciplinary open access archive for the deposit and dissemination of scientific research documents, whether they are published or not. The documents may come from teaching and research institutions in France or abroad, or from public or private research centers.
L'archive ouverte pluridisciplinaire HAL, est destinée au dépôt et à la diffusion de documents scientifiques de niveau recherche, publiés ou non, émanant des établissements d'enseignement et de recherche français ou étrangers, des laboratoires publics ou privés. 


\title{
Integrating Random Shocks into Multi-State Physics Modelsof
}

\section{Degradation ProcessesforComponent Reliability Assessment}

Yan-Hui Lin, Yan-FuLi,member IEEE, Enrico Zio,senior member IEEE ${ }^{\mathbf{1}}$

Index Terms - Component degradation,random shocks,multi-state physics model, semi-Markov process, Monte Carlo simulation.

\begin{abstract}
We extend a multi-state physics model (MSPM) framework for component reliability assessment by including semi-Markov and random shockprocesses. Two mutually exclusivetypes of random shocks are considered: extreme, and cumulative.Extreme shockslead the component to immediate failure, whereascumulative shockssimplyaffect the componentdegradation rates. General dependences between the degradation and the two types of random shocks are considered. A Monte Carlo simulation algorithmis implemented to compute component state probabilities. An illustrative example is presented,and a sensitivity analysis is conducted on themodel parameters. The resultsshowthat our extended model is able to characterize the influences of different types of random shocks onto the component state probabilities and the reliability estimates.
\end{abstract}

Y.H.Lin and Y.F.LiarewiththeChaironSystemsScienceandtheEnergetic Challenge, European Foundation for New Energy-Electricite' de France, EcoleCentrale Paris-Supelec, 91192 Gif-sur-Yvette, France (e-mail: yanhui.lin@ecp.fr; yanfu.li@ecp.fr; yanfu.li@supelec.fr)

E. Zio is with the Chair on Systems Science and the Energetic Challenge, European Foundation for New Energy-Electricite' de France, EcoleCentrale Paris-Supelec, 91192 Gif-sur-Yvette, France, and also with the Politecnico di Milano, 20133 Milano, Italy (e-mail: enrico.zio@ecp.fr; enrico.zio@supelec.fr; enrico.zio@polimi.it) 


\section{Abbreviation}

MSPM Multi-state physics model

\section{Notations}

$\boldsymbol{S} \quad$ The states set of component degradation processes

$\tau_{i} \quad$ The residence time of component being in the state i since the last transition

$\boldsymbol{\theta} \quad$ The external influencing factors

$\lambda_{i, j}\left(\tau_{i}, \boldsymbol{\theta}\right) \quad$ The transition rate between state $i$ and state $j$

$t \quad$ Time

$(t, t+\Delta t) \quad$ Infinitesimal time interval

$X_{k} \quad$ The state of the component after $k$ transitions

$T_{k} \quad$ The time of arrival at $X_{k}$ of component

$P(t) \quad$ The state probability vector

$p_{i}(t) \quad$ The probabilityof component being in state $i$ at time $t$

$R(t) \quad$ The component reliability

$N(t) \quad$ The number of random shocks that occurredbefore and up tot

$\mu \quad$ The constant arrival rate of random shocks

$\tau_{i, m}^{\prime} \quad$ The residence time of the component in the current degradation state $i$ after $m$ cumulative shocks

$p_{i, m}\left(\tau_{i, m}^{\prime}\right)$ The probability that one shock results in extreme damage

$\lambda_{i, j}^{(m)}\left(\tau_{i, m}^{\prime}, \boldsymbol{\theta}\right) \quad$ The transition rates after $m$ cumulative random shocks

$\boldsymbol{S}^{\prime} \quad$ The state space of the integrated model

$\lambda_{(i, m),(j, n)}\left(\tau_{i, m}^{\prime}, \boldsymbol{\theta}\right) \quad$ The transition rate between state $(i, m)$ and state $(j, n)$

$f_{(i, m),(j, n)}\left(\tau_{i, m}^{\prime} \mid t, \boldsymbol{\theta}\right)$ The transition probability density function

$N_{\max } \quad$ The maximum number of replications

$\widehat{\boldsymbol{P}}(t)=\left\{\widehat{p_{M}}(t), \widehat{p_{M-1}}(t), \ldots, \widehat{p_{0}}(t)\right\} \quad$ The estimation of the state probability vector

$\operatorname{var}_{\widehat{p_{i}}}(t) \quad$ The sample variance of estimated state probability $\widehat{p}_{i}(t)$

$\delta \quad$ The predetermined constantwhich controls the influence of the degradation onto the probability $p_{i, m}\left(\tau_{i, m}^{\prime}\right)$

$\varepsilon \quad$ The relative increment of transition rates after one cumulative shock happens

\section{INTRODUCTION}

Failures of components generally occur in two modes: degradation failures due to physical deterioration in the form of wear, erosion, fatigue, etc.; and catastrophic 
failures due to damages caused by sudden shocks in the form of jolts, blows, etc.[1]-[2].

In the past decades, a number of degradation models have been proposed in the fieldof reliability engineering[3]-[9]. They can be grouped into several categories [9]: statistical distributions (e.g. Bernstein distribution[3]),stochastic processes (e.g. Gamma process, and Wiener process) [4]-[5], andmulti-state models [6]-[8].

Most of the existingmodelsare typically built on degradation datafromhistorical collections [3], [5]-[7], ordegradation tests [4], which however are suited for components ofrelatively low cost or/andhigh failure rate(s) (e.g. electronic devices, and vehicle components) [10]-[12].In industrial systems, there are a number of critical components (e.g. valves and pumps in nuclear power plantsor aircraft [13]-[14], engines of airplanes, etc.) designed to be highly reliable to ensure system operation and safety, but for which degradation experiments arecostly. In practice, it is thenoften difficult to collectsufficient degradation or failuresamples to calibrate the degradation models mentioned above.

An alternative isto resort to failure physics and structural reliability, to incorporate knowledgeon thephysics of failure of the particular component (passive and active)[13]-[17]. Recently, Unwin et al. [16] have proposed a multi-state physics model (MSPM) for modeling nuclear component degradation, also accounting for the effects of environmental factors (e.g. temperature and stress) within certain predetermined ranges [17].In a previous work by the authors [9], the modelhas been formulated under the framework of inhomogeneous continuous time Markov chains, and solved by Monte Carlo simulation.

Random shocks need to be accounted foron top of the underlying degradation processes because they can bring variations to influencing environmental factors, even outside their predetermined boundaries [18], that can accelerate the degradation processes.For example,thermal, and mechanical shocks (e.g.internal thermal shocks and water hammers)[17],[19]-[20]onto power plant componentscan lead to intense increases intemperatures, and stresses, respectively;under theseextreme conditions, the original physics functions in MSPM might be insufficient to characterize the 
influences of random shocks onto the degradation processes, and must, therefore, be modified.In the literature, random shocks are typically modeled by Poisson processes[1], [18], [21]-[23], distinguishing two main types, extreme shock and cumulative shock processes [21], according to the severity of the damage. The former could directly lead the component to immediate failure[24]-[25], whereas the latter increasesthe degree of damagein a cumulative way [26]-[27].

Random shockshave been intensively studied [1]-[2], [22]-[23],[28]-[33]. Esaryet al. [23] haveconsideredextreme shocksin a component reliability model, whereas Wanget al. [2], Klutke and Yang [30], and Wortmanetal. [31] have modeledthe influences of cumulative shocks ontoa degradation process.Both extreme and cumulative random shocks have been considered by Li and Pham[1], and Wang and Pham [22]. Additionally, Ye et al. [28], and Fan et al. [29] have considered that a high severity of degradation can lead to a high probability thata random shock causes extreme damage.However, the fact that theeffects of cumulative shocks can vary according to the severity of degradationhas alsoto be considered.

Among the models mixing the multi-state degradation models and random shocks, $\mathrm{Li}$ and Pham [1] divided the underlining continuous and monotonically increasing degradation processes into a finite number of states, and combined them with $s$-independent random shocks. Wang and Pham [22] further considered the dependences among the continuous and monotone (increasing or decreasing) degradation processes, and between degradation processes and random shocks. Yang et al. [33] integrated random shocks into a Markov degradation model. Becker et al. [32] combined a semi-Markov degradation model, which is more general than Markov model, with random shocks in a dynamic reliability formulation, where the influence of random shocks is characterized by the change of continuous degradation variables (e.g. structure strength). To ourknowledge, this is the first work of semi-Markov degradation modeling that represents the influence of random shocks by changing the transition rates, which might also be physics functions.

The contribution of the paper is that it generalizes the MSPM framework to handle both degradation and random shocks, which have not been previously 
considered by the existing MSPMs. First, we extend our previous MSPM framework [9] to semi-Markov modeling, which more generallydescribes the fact that the time of transition to a state can dependon the residence time in the current state, and hence is more suitable for including maintenance[34]. Then,we propose a general random shock model, where the probability of a random shock resulting in extreme or cumulativedamage, and the cumulative damages, are both $s$-dependent on the current component degradation condition (the component degradation state, and residence time in the state).Finally, we integrate the random shock model into the MSPM frameworkto describe the influence of random shocks on the degradation processes. The rest of this paper is organized as follows. Section 2 introduces the semi-Markov scheme into the MSPM framework. Section 3 presents the random shock model;in Section 4, its integration into MSPM is presented. Monte Carlo simulation procedures to solve the integrated model are presented in Section 5. Section 6 uses a numerical example regarding a case studyto illustrate the proposed model. Section 7 concludes the work.

\section{A MSPM OF COMPONENT DEGRADATION PROCESSES}

A continuous-time stochastic process is called a semi-Markov processif the embedded jump chainis a Markov Chain and the times between transitionsmay berandom variables with any distribution [35].The following assumptions are madefor the extended MSPM framework [9] based on semi-Markov processes.

- The degradation process hasa finite number of states $\boldsymbol{S}=\{0,1, \ldots, M\}$ where states 0 , and $M$ represent the complete failure state, and perfect functioning state, respectively. The generic intermediate degradation statesi $(0<i<M)$ are established according to the degradation development and condition, wherein the component isfunctioning or partiallyfunctioning.

- The degradation follows a continuous-time semi-Markov process;the transition rate between state $i$ and state $j$, denoted by $\lambda_{i, j}\left(\tau_{i}, \boldsymbol{\theta}\right)$, is a function of $\tau_{i}$ whichis the residence time of thecomponent being in the current state 
$i$ since the last transition, and $\boldsymbol{\theta}$ whichrepresents the external influencing factors (including physical factors).

- The initial state (at time $t=0$ ) of the component is $M$.

- Maintenance can be carried out from any degradation state, except for the complete failure state (in other words, there is no repair from failure).

Fig. 1 presents the diagram of the semi-Markov component degradation process.

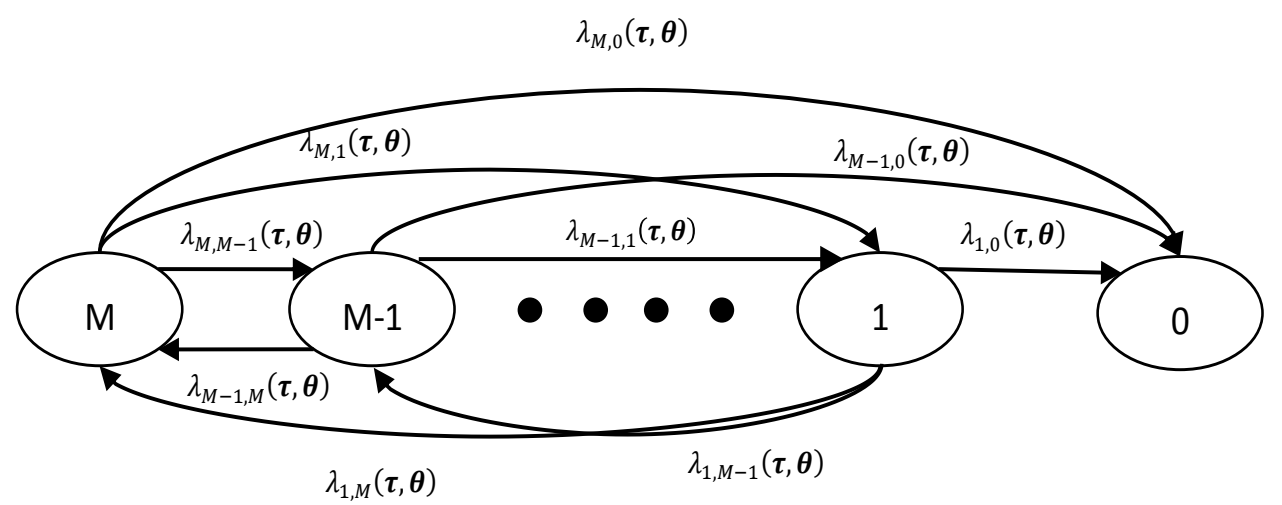

Fig. 1.The diagram of the semi-Markov process.

The probability that the continuous time semi-Markov process will step to statej in the next infinitesimal time interval $(t, t+\Delta t)$, given that it has arrived at state $i$ at time $T_{n}$ after $n$ transitions and remained stable in $i$ from $T_{n}$ until time $t$, isdefined as

$$
\begin{aligned}
& P\left[X_{n+1}=j, T_{n+1} \in[t, t+\Delta t] \mid\left\{X_{k}, T_{k}\right\}_{k=0}^{n-1},\left(X_{n}=i, T_{n}\right), T_{n} \leq t \leq T_{n+1}, \boldsymbol{\theta}\right] \\
& =P\left[X_{n+1}=j, T_{n+1} \in[t, t+\Delta t] \mid\left(X_{n}=i, T_{n}\right), T_{n} \leq t \leq T_{n+1}, \boldsymbol{\theta}\right] \\
& =\lambda_{i, j}\left(\tau_{i}=t-T_{n}, \boldsymbol{\theta}\right) \Delta t, \forall i, j \in \boldsymbol{S}, i \neq j .(1)
\end{aligned}
$$

where $X_{k}$ denotes the state of the component after $k$ transitions. The degradation transition rates can be obtained from the structural reliability analysisofthe degradation processes (e.g. the crack propagation process [15], [17], whereas the transition rates related to maintenance tasks can be estimated from the frequencies of maintenance activities).For example, the authors of [17] divided the degradation process of the alloy metal weld into six states dependent on the underlying physics 
phenomenon, and some degradation transition rates are represented by corresponding physics equations.

The solution tothe semi-Markov process model is the state probability $\operatorname{vector} P(t)=\left\{p_{M}(t), p_{M-1}(t), \ldots, p_{0}(t)\right\}$. Because no maintenance is carried out from the component failure state, and the component is regarded as functioning in all other intermediate alternative states, its reliability can be expressed as

$$
R(t)=1-p_{0}(t) .
$$

Analyticallysolving the continuous time semi-Markov model with state residence time-dependent transition rates is a difficult or sometimes impossible task, andthe Monte Carlo simulation method is usuallyapplied to obtain $P(t)$ [36]-[37].

\section{RANDOM SHOCKS}

The followingassumptions are madeon the random shock process.

- The arrivals of random shocks follow a homogeneous Poisson process $\{N(t), t \geq 0\}[21]$ with constant arrival rate $\mu$. The random shocks are $s$-independent of the degradation process, but they can influence the degradation process (see Fig. 2).

- The damages of random shocks aredivided into two types: extreme, and cumulative.

- Extreme shock and cumulative shock are mutually exclusive.

- The component failsimmediately upon occurrence of extreme shocks.

- The probability of a random shock resulting in extreme or cumulative damageiss-dependent on the current component degradation.

- The damageof cumulative shockscan only influence the degradation transition departing from the current state, and its impact on the degradation process is $s$-dependent on the current component degradation. 

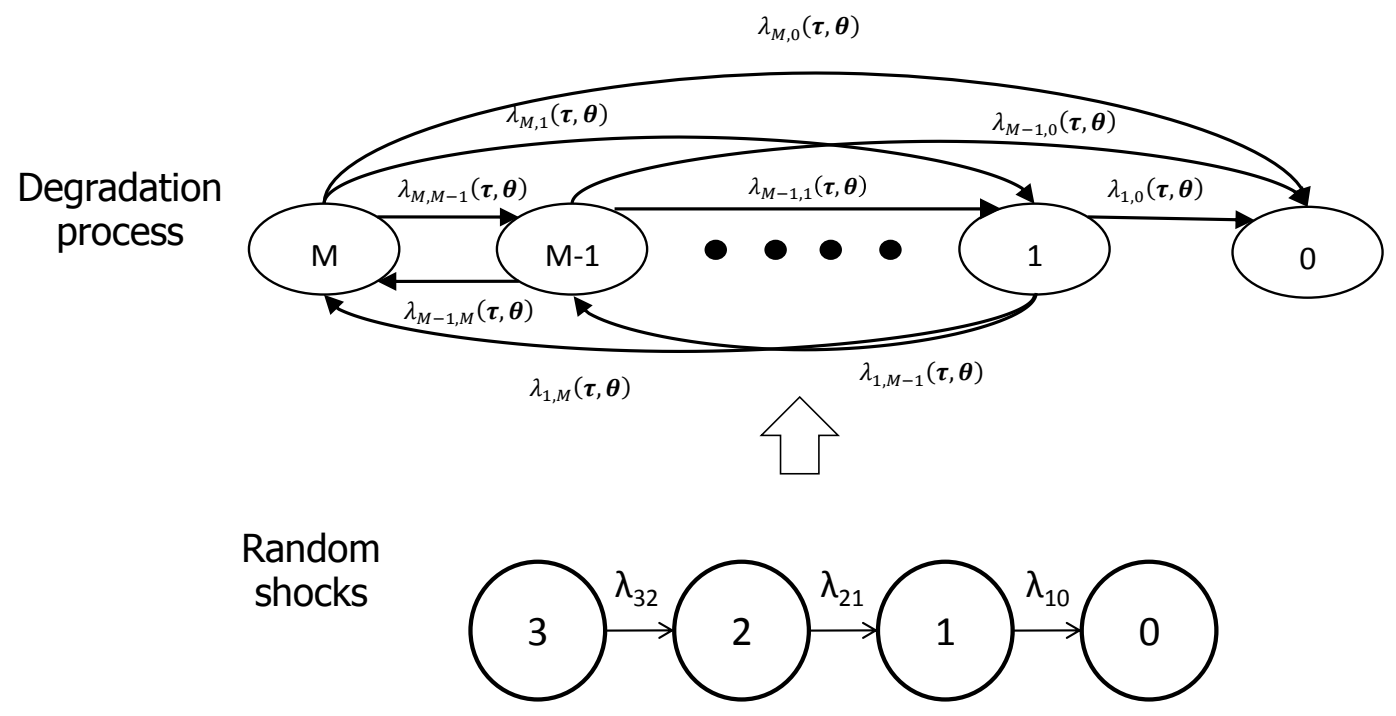

Fig. 2. Degradation andrandom shock processes.

The first five assumptions are takenfrom [22]. The sixthassumption reflects the aging effects addressed in Fan et al.'s shock model [29], where the random shocks are more fatal to the component (i.e. more likely lead to extreme damages)when the component is in severe degradation states.However, the influences of cumulative shocksunderaging effects have not been consideredin Fan et al.'s model.In addition, the random shock damage is assumed to depend on the current degradation, characterizedby three parameters: 1)the current degradation statei,2)the number of cumulative shocks $m$ that occurred while in the current degradation state since the last degradation state transition, and3)the residence time $\tau_{i, m}^{\prime}$ ofthe component inthe current degradation state iaftermcumulative $\operatorname{shocks} \tau_{i, m}^{\prime} \geqslant 0$.

Let $p_{i, m}\left(\tau_{i, m}^{\prime}\right)$ denote the probability that one shock results in extreme damage (thecumulative damageprobability is then $1-p_{i, m}\left(\tau_{i, m}^{\prime}\right)$ ). In the case of cumulative shock, the degradation transition rates for the current state change at the moment of the occurrence of the shock, whereas the other transition rates are not affected.Let $\lambda_{i, j}^{(m)}\left(\tau_{i, m}^{\prime}, \boldsymbol{\theta}\right)$ denote the transition rates after $m$ cumulative random shocks, where $\lambda_{i, j}^{(0)}\left(\tau_{i, 0}^{\prime}, \boldsymbol{\theta}\right)$ holds the same expression asthe transition rate $\lambda_{i, j}\left(\tau_{i, 0}^{\prime}, \boldsymbol{\theta}\right)$ in the pure degradation model, and the other transition rates (i.e. $m>0$ ) depend on thedegradation 
and the external influencing factors.Because the influences of random shocks can render invalid the original physics functions, we propose a general model which allows the formulation of physics functions dependent on the effects of shocks. The modified transition rates can be obtained bymaterial science knowledge, and data from shock tests [38].These quantities will be used as the key linking elements in the integration work of the next section.

\section{INTEGRATION OF RANDOM SHOCKS IN THE MSPM}

Based on the first and second assumptions on random shocks, the new model that integrates random shocks into MSPM is shown in Fig 3. In the model, the states of the component are represented by pair $(i, m)$, where $i$ is the degradation state, and $m$ is the number of cumulative shocks that occurred during the residence time in the current state. For all the degradation states of the component except for state 0 , the number of cumulative shocks could range from $O$ to positive infinity. If the transition to a new degradation state occurs, the number of cumulative shocks is set to 0 , coherently with the last assumption on random shocks. The state space of the new integrated model is denoted by $\boldsymbol{S}^{\prime}=\{(M, 0),(M, 1),(M, 2), \ldots,(M-1,0),(M-1,1), \ldots,(0,0)\} \quad$.The component is failed whenever the model reaches $(0,0)$. The transition ratedenoted by $\lambda_{(i, m),(j, n)}\left(\tau_{i, m}^{\prime}, \boldsymbol{\theta}\right)$ is residence time-dependent, thus rendering the process a continuous time semi-Markov process. 


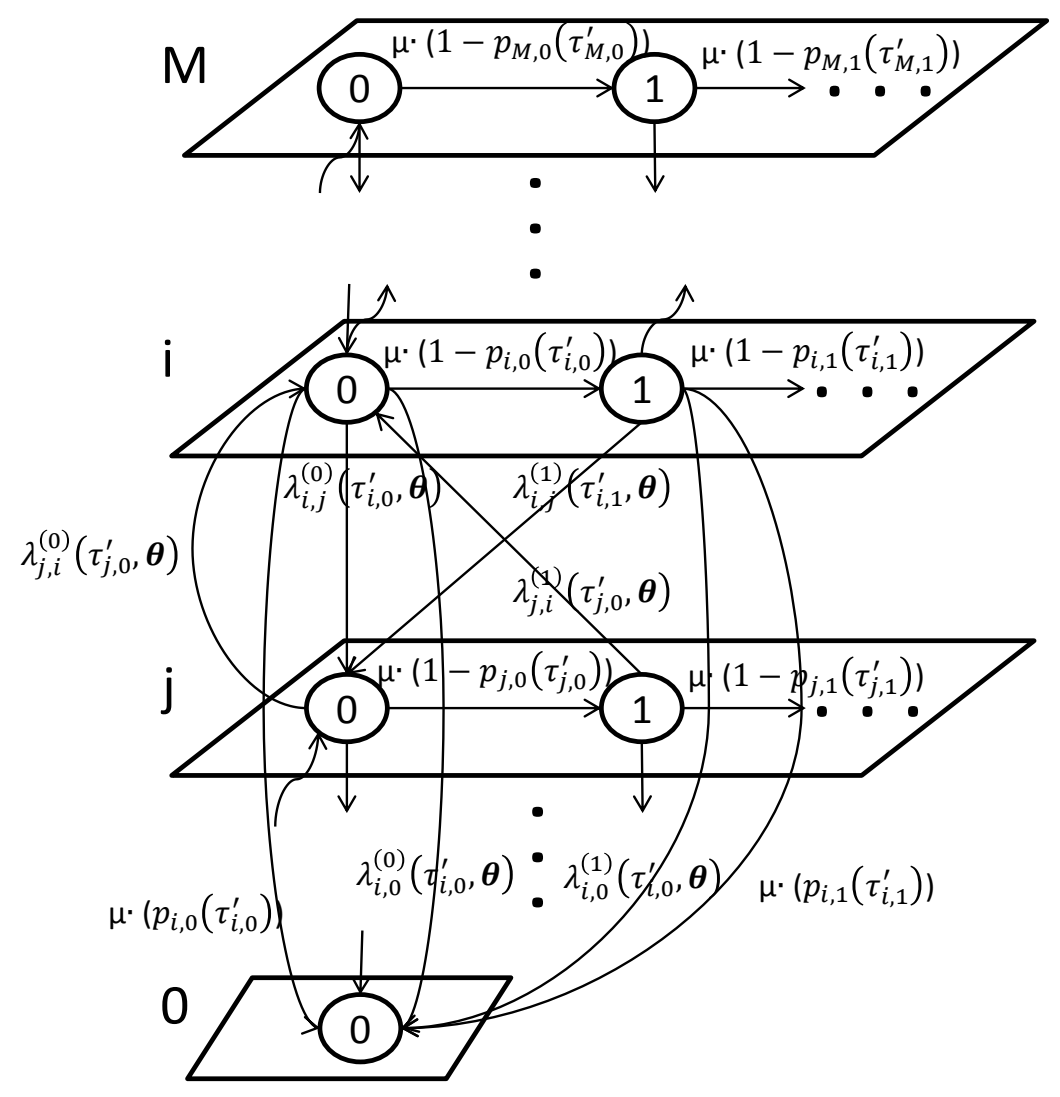

Fig. 3.Degradation and random shock processes.

Suppose that the component is in a non-failure state $(i, m)$; then,we have three types of outgoing transition rates:

$$
\lambda_{(i, m),(0,0)}\left(\tau_{i, m}^{\prime}, \boldsymbol{\theta}\right)=\mu \cdot\left(p_{i, m}\left(\tau_{i, m}^{\prime}\right)\right),
$$

the rate of occurrence of an extreme shock which will cause the component to go to state $(0,0)$;

$$
\lambda_{(i, m),(i, m+1)}\left(\tau_{i, m}^{\prime}, \boldsymbol{\theta}\right)=\mu \cdot\left(1-p_{i, m}\left(\tau_{i, m}^{\prime}\right)\right),
$$

the rate of occurrence of a cumulative shock which will cause the component to go to state $(i, m+1) ;$ and

$$
\lambda_{(i, m),(j, 0)}\left(\tau_{i, m}^{\prime}, \boldsymbol{\theta}\right)=\lambda_{i, j}^{(m)}\left(\tau_{i, j}^{\prime}, \boldsymbol{\theta}\right),
$$

therate of transition (i.e. degradation or maintenance) which will cause the component to make the transition to state $(\mathrm{j}, 0)$.

The effect of random shocks on the degradation processes is shown in (5) by using 
the superscript $(m)$, where $m$ is the number of cumulative shocks occurring during the residence time in the current state. It means that the transition rate functions depend on the number of cumulative shocks. This is a general formulation.

The first two types (3), (4) depend on the probability of a random shock resulting in extreme damage, and in cumulative damage, respectively; the last type of transition rates (5) depends on the cumulative damage of random shocks.In this model, we do not directly associate a failure threshold to the cumulative shocks, because the damage of cumulative shocks can only influence the degradation transition departing from the current state, and its impact on the degradation process is $s$-dependent on the current component degradation. The cumulative shocks can only aggravate the degradation condition of the component instead of leading it suddenly to failure (which is the role of extreme shocks). The effect of the cumulative shocks is reflected in the change of transition rates. The probability of a shock becoming an extreme one depends on the degradation condition of the component. The extreme shocks immediately lead the component to failure, whereas the damage of cumulative shocks accelerates the degradation processes of the component.

The proposed model is based on a semi-Markov process and random shocks. Under this general structure, as explained in the paragraph above, the physics lies in the transition rates of the semi-Markov process. We refer to it as a physics model because the stressors (e.g. the crack in the case study) that cause the component degradation are explicitly modeled, differently from the conventional way of estimating the transition rates from historical failure and degradation data, which are relatively rare for the critical components. More information aboutMSPM can be found in [9]. In addition, the random shocks are integrated into the MSPM in a way that they may change the physics functions of the transition rates, within a general formulation.

Similarly to what was said for the semi-Markov process presented in Section 2, the state probabilities of the new integrated model can be obtained by Monte Carlo simulation, and the expression of component reliability is 


$$
R(t)=1-p_{(0,0)}(t)
$$

\section{RELIABILITY ESTIMATION}

\subsection{Basics of Monte Carlo simulation}

The key theoretical construct upon which Monte Carlo simulation is based is the transition probability density function $f_{(i, m),(j, n)}\left(\tau_{i, m}^{\prime} \mid t, \boldsymbol{\theta}\right)$, defined as

$f_{(i, m),(j, n)}\left(\tau_{i, m}^{\prime} \mid t, \boldsymbol{\theta}\right) d \tau_{i, m}^{\prime} \equiv$ theprobability that, given that the system arrives at the state $(i, m)$ at time $t$, with physical factors $\boldsymbol{\theta}$, the next transition will occur in the infinitesimal timeinterval $\left(t+\tau_{i, m}^{\prime}, t+\tau_{i, m}^{\prime}+d \tau_{i, m}^{\prime}\right)$, and will be tothe state $(j, n)[36]$.

By using the previously introduced transition rates, (7) can be expressed as

$$
f_{(i, m),(j, n)}\left(\tau_{i, m}^{\prime} \mid t, \boldsymbol{\theta}\right) d \tau_{i, m}^{\prime}=P_{(i, m)}\left(\tau_{i, m}^{\prime} \mid t, \boldsymbol{\theta}\right) \lambda_{(i, m),(j, n)}\left(\tau_{i, m}^{\prime}, \boldsymbol{\theta}\right) d \tau_{i, m}^{\prime} .
$$

$P_{(i, m)}\left(\tau_{i, m}^{\prime} \mid t, \boldsymbol{\theta}\right)$ is the probability that, given thatthe component arrives at the state $(i, m)$ at time $t$ with physical factors $\boldsymbol{\theta}$, no transition will occur in the time interval $\left(t, t+\tau_{i, m}^{\prime}\right)$.It satisfies

$$
\frac{d P_{(i, m)}\left(\tau_{i, m}^{\prime} \mid t, \boldsymbol{\theta}\right)}{P_{(i, m)}\left(\tau_{i, m}^{\prime} \mid t, \boldsymbol{\theta}\right)}=-\lambda_{(i, m)}\left(\tau_{i, m}^{\prime}, \boldsymbol{\theta}\right) d \tau_{i, m}^{\prime}
$$

$\lambda_{(i, m)}\left(\tau_{i, m}^{\prime}, \boldsymbol{\theta}\right) d \tau_{i, m}^{\prime}$ is the conditional probability that, given that the component is in the state $(i, m)$ at time $t$, having arrived there at time $t-\tau_{i, m}^{\prime}$, with physical factors $\boldsymbol{\theta}$, it will depart from $(i, m)$ during $\left(t, t+d \tau_{i, m}^{\prime}\right) \cdot \lambda_{(i, m)}\left(\tau_{i, m}^{\prime}, \boldsymbol{\theta}\right)$ is obtained as

$$
\lambda_{(i, m)}\left(\tau_{i, m}^{\prime}, \boldsymbol{\theta}\right)=\sum_{\left(i^{\prime}, m^{\prime}\right)} \lambda_{(i, m),\left(i^{\prime}, m^{\prime}\right)}\left(\tau_{i, m}^{\prime}, \boldsymbol{\theta}\right) .
$$

Taking the integral of both sides of (9) with the initial condition $P_{(i, m)}(0 \mid t, \boldsymbol{\theta})=1$, we obtain

$$
P_{(i, m)}\left(\tau_{i, m}^{\prime} \mid t, \boldsymbol{\theta}\right)=\exp \left[-\int_{0}^{\tau_{i, m}^{\prime}} \lambda_{(i, m)}(s, \boldsymbol{\theta}) d s\right] .
$$

Substituting (11) into (8), we obtain

$$
f_{(i, m),(j, n)}\left(\tau_{i, m}^{\prime} \mid t, \boldsymbol{\theta}\right)=\lambda_{(i, m),(j, n)}\left(\tau_{i, m}^{\prime}, \boldsymbol{\theta}\right) \exp \left[-\int_{0}^{\tau_{i, m}^{\prime}} \lambda_{(i, m)}(s, \boldsymbol{\theta}) d s\right] .
$$

To derive a Monte Carlo simulation procedure, (12) is rewritten as 


$$
\begin{aligned}
& f_{(i, m),(j, n)}\left(\tau_{i, m}^{\prime} \mid t, \boldsymbol{\theta}\right) \\
& =\frac{\lambda_{(i, m),(j, n)}\left(\tau_{i, m}^{\prime}, \boldsymbol{\theta}\right)}{\lambda_{(i, m)}\left(\tau_{i, m}^{\prime}, \boldsymbol{\theta}\right)} \cdot \lambda_{(i, m)}\left(\tau_{i, m}^{\prime}, \boldsymbol{\theta}\right) \exp \left[-\int_{0}^{\tau_{i, m}^{\prime}} \lambda_{(i, m)}(s, \boldsymbol{\theta}) d s\right] \\
& \quad=\pi_{(i, m),(j, n)}\left(\tau_{i, m}^{\prime} \mid \boldsymbol{\theta}\right) \cdot \psi_{(i, m)}\left(\tau_{i, m}^{\prime} \mid \boldsymbol{\theta}\right)
\end{aligned}
$$

$\psi_{(i, m)}\left(\tau_{i, m}^{\prime} \mid \boldsymbol{\theta}\right)$ is the probability density function for the holding time $\tau_{i, m}^{\prime}$ inthe state $(i, m)$, given the physical factors $\boldsymbol{\theta}$. It satisfies

$$
\begin{array}{r}
\psi_{(i, m)}\left(\tau_{i, m}^{\prime} \mid \boldsymbol{\theta}\right)=\lambda_{(i, m)}\left(\tau_{i, m}^{\prime}, \boldsymbol{\theta}\right) \exp \left[-\int_{0}^{\tau_{i, m}^{\prime}} \lambda_{(i, m)}(s, \boldsymbol{\theta}) d s\right] . \\
\pi_{(i, m),(j, n)}\left(\tau_{i, m}^{\prime} \mid \boldsymbol{\theta}\right)=\frac{\lambda_{(i, m),(j, n)}\left(\tau_{i, m}^{\prime}, \boldsymbol{\theta}\right)}{\lambda_{(i, m)}\left(\tau_{i, m}^{\prime}, \boldsymbol{\theta}\right)},
\end{array}
$$

is regarded as the conditional probability that, for the transition out of state $(i, m)$ after holding time $\tau_{i, m}^{\prime}$, with the physical factors $\boldsymbol{\theta}$, the transition arrival state will be $(j, n)$.

In the Monte Carlo simulation, for the component arriving atany non-failurestate $(i, m)$ at any time $t$, the process at first samples the holding time at state $(i, m)$ corresponding to (14), and then determines the transition arrival state $(j, n)$ from state $(i, m)$ according to (15). This procedure is repeated until the accumulated holding time reaches the predefined time horizon,or the component reaches the failurestate $(0,0)$.

\subsection{The simulation procedure}

To generate the holding time $\tau_{i, m}^{\prime}$ and the next state $(j, n)$ for the component arriving in any non-failure state $(i, m)$ at any time $t$,oneproceeds as follows. Two uniformly distributed random numbers $u_{1}$ and $u_{2}$ are sampled in the interval $[0,1]$; then, $\tau_{i, m}^{\prime}$ is chosen so that

$$
\int_{0}^{\tau_{i, m}^{\prime}} \lambda_{(i, m)}(s, \boldsymbol{\theta}) d s=\ln \left(1 / u_{1}\right),(1
$$

and $(j, n)=a^{*}$ that satisfies

$$
\sum_{k=0}^{a^{*}-1} \lambda_{(i, m), k}\left(\tau_{i, m}^{\prime}, \boldsymbol{\theta}\right)<u_{2} \lambda_{(i, m)}\left(\tau_{i, m}^{\prime}, \boldsymbol{\theta}\right) \leq \sum_{k=0}^{a^{*}} \lambda_{(i, m), k}\left(\tau_{i, m}^{\prime}, \boldsymbol{\theta}\right)(17)
$$

where $a^{*}$ represents one state in the ordered sequence of all possibleoutgoing states of state $(i, m)$.The state $a^{*}$ is determined by going through the ordered sequence of all 
possible outgoing states of state $(i, m)$ until (17) is satisfied.The algorithm ofMonte Carlo simulation for solving the integrated MSPMon a time horizon $\left[0, t_{\max }\right]$ is presented as follows.

Set $N_{\max }$ (the maximum number of replications), and $k=0$.

While $k<N_{\max }$, do the following.

Initialize the system by setting $s=(M, 0)$ (initial state of perfect performance), setting the time $t=0$ (initial time).

Set $t^{\prime}=0$ (state holding time).

While $t<t_{\max }$, do the following.

Calculate (10).

Sample at'by using(16).

Sample anarrival state $(j, n)$ by using $(17)$.

Set $t=t+t^{\prime}$.

Set $s=(j, n)$.

If $s=(0,0)$,

thenbreak.

End if.

End While.

Set $k=k+1$.

End While.

The estimation of thestate probability vector $\widehat{\boldsymbol{P}}(t)=\left\{\widehat{p_{M}}(t), \widehat{p_{M-1}}(t), \ldots, \widehat{p_{0}}(t)\right\}$ at time $t$ is

$$
\widehat{\boldsymbol{P}}(t)=\frac{1}{N_{\max }}\left\{n_{M}(t), n_{M-1}(t), \ldots, n_{0}(t)\right\}
$$

where $\left\{n_{i}(t) \mid i=M, \ldots, 0, t \leq t_{\max }\right\}$ is the total number of visits to state $i$ at time $t$,with sample variance[39]defined as

$$
\operatorname{var}_{\widehat{p_{i}}(t)}=\widehat{p}_{i}(t)\left(1-\widehat{p}_{i}(t)\right) /\left(N_{\text {max }}-1\right) \cdot(19)
$$




\section{CASE STUDY AND RESULTS}

\subsection{Case study}

We illustrate the proposed modeling framework on a case study slightly modified from an Alloy 82/182 dissimilar metal weld in a primary coolant system of a nuclear power plant in [17]. The MSPM of the original crack growth is shown in Fig. 4.

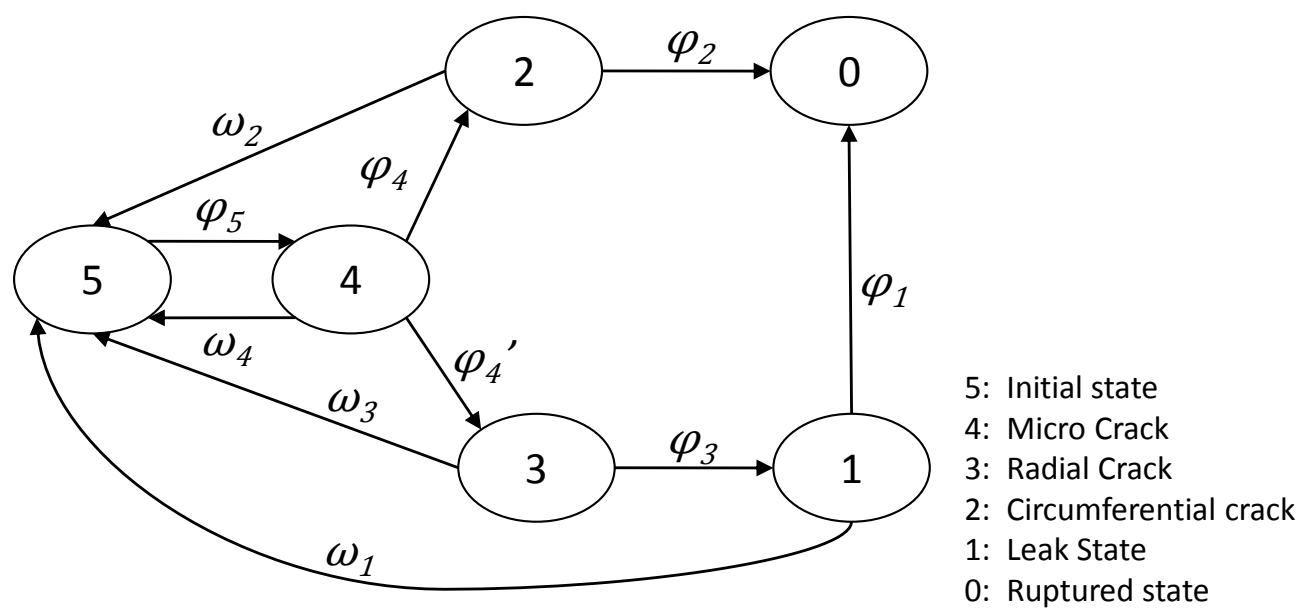

Fig.4.MSPM of crackdevelopment in Alloy 82/182 dissimilar metal welds.

where $\varphi_{i}$, and $\omega_{i}$ represent the degradation transition rate, and maintenance transition rate, respectively.Except for $\varphi_{5}, \varphi_{4}, \varphi_{4}$,and $\varphi_{3}$, all the other transition rates are assumed to be constant. The expressions of the variabletransition rates are

$$
\begin{aligned}
& \varphi_{5}=\left(\frac{b}{\tau}\right) \cdot\left(\frac{\tau_{5}}{\tau}\right)^{b-1} \\
& \varphi_{4}=\left\{\begin{array}{cl}
\frac{a_{C} P_{C}}{\dot{a}_{M} \tau_{4}^{2}\left(1-P_{C}\left(1-a_{C} /\left(u \dot{a}_{M}\right)\right)\right)}, & \text { if } \tau_{4}>a_{C} / \dot{a}_{M} \\
0, & \text { else; }
\end{array}\right. \\
& \varphi_{4}{ }^{\prime}=\left\{\begin{array}{cl}
\frac{a_{D} P_{D}}{\dot{a}_{M} \tau_{4}^{2}\left(1-P_{D}\left(1-a_{D} /\left(u \dot{a}_{M}\right)\right)\right)}, & \text { if } \tau_{4}>a_{D} / \dot{a}_{M} \\
0, & \text { else } ;
\end{array}\right. \\
& \varphi_{3}= \begin{cases}\frac{1}{\tau_{3}}, & \text { if } \tau_{3}>\left(a_{L}-a_{D}\right) / \dot{a}_{M} \\
0, & \text { else. }\end{cases}
\end{aligned}
$$

The other transition rates andthe parametersvalues are presented in Table I. 
Table I

Parameters and constant transition rates [17]

\begin{tabular}{|l|l|}
\hline$b$-Weibull shape parameter for crack initiation model & 2.0 \\
\hline$\tau$-Weibull scale parameter for crack initiation model & 4 years \\
\hline$a_{D}-$ Crack length threshold for radial macro-crack & $10 \mathrm{~mm}$ \\
\hline$P_{D}-$ Probability that micro-crack evolves as radial crack & 0.009 \\
\hline$\dot{a}_{M}-$ Maximum credible crack growth rate & $9.46 \mathrm{~mm} / \mathrm{yr}$ \\
\hline$a_{C}-$ Crack length threshold for circumferential macro-crack & $10 \mathrm{~mm}$ \\
\hline$P_{C}-$ Probability that micro-crack evolves as circumferential crack & 0.001 \\
\hline$a_{L}-$ Crack length threshold for leak & $20 \mathrm{~mm}$ \\
\hline$\omega_{4}-$ Repair transition rate from micro-crack & $1 \times 10-3 / \mathrm{yr}$ \\
\hline$\omega_{3}-$ Repair transition rate from radial macro-crack & $2 \times 10-2 / \mathrm{yr}$ \\
\hline$\omega_{2}-$ Repair transition rate from circumferential macro-crack & $2 \times 10-2 / \mathrm{yr}$ \\
\hline$\omega_{1}-$ Repair transition rate from leak & $8 \times 10-1 / \mathrm{yr}$ \\
\hline$\varphi_{1}-$ Leak to rupture transition rate & $2 \times 10-2 / \mathrm{yr}$ \\
\hline$\varphi_{2}-$ Macro-crack to rupture transition rate & $1 \times 10-5 / \mathrm{yr}$ \\
\hline
\end{tabular}

The random shockscorrespond to the thermal and mechanical shocks(e.g.internal thermal shocks and water hammers) [17], [19]-[20] applied to the dissimilar metal welds. The damage of random shocks can accelerate the degradation processes, and hence increase the rate of component degradation. Note that Yang et al[33]have related random shocks to the degradation rates in their work.To assess the degree of impact of shocks, we may use 1) physics functions for the influence of random shocks through material science knowledge; and 2) transition times, speed of cracking development, and other related information obtained from shock tests [38].We setthe occurrencerate $\mu=1 / 15 y^{-1}$, and the probability of a random shock becomingan extreme shock as $p_{i, m}\left(\tau_{i, m}^{\prime}\right)=1-\exp \left[-\delta m(6-i)\left(2-e^{-\tau_{i, m}^{\prime}}\right)\right]$, taking the exponential formulationfromFan et al.'s work [29].In this formula, we use $m(6-$ $i)\left(2-e^{-\tau_{i, m}^{\prime}}\right)$ to quantify the component degradation.It is noted that the quantity $2-e^{-\tau_{i, m}^{\prime}}$ ranges from 1 to 2 , representing the relatively small effect of $\tau_{i, m}^{\prime}$ onto the degradation situation in comparison with theother two parameters $m$ and $i$, and $\delta$ is a predetermined constantwhich controls the influence of the degradation onto the probability $p_{i, m}\left(\tau_{i, m}^{\prime}\right)$. In this study, we set $\delta=0.0001$. The value of $\delta$ was set 
considering the balance between showing the impact of extreme shocks and reflecting the high reliability of the critical component.In addition, we assume the corresponding degradation transition rates after $m$ cumulative shocksto be $\lambda_{i, j}^{(m)}\left(\tau_{i, m}^{\prime}, \boldsymbol{\theta}\right)=(1+$ $\varepsilon)^{m} \lambda_{i, j}\left(\tau_{i, m}^{\prime}, \boldsymbol{\theta}\right)$, where $\varepsilon=0.3$ is the relative increment of transition rates after one cumulative shock happens, and the formulation $(1+\varepsilon)^{m}$ is used to characterize the accumulated effect of such shocks. To characterize the increase of the transition rates, in the case study we have used the parameter $\varepsilon$ to represent the relative increment of degradation transition rate after one cumulative shock occurs.For the sake of simplicity, but without loss of generality in the framework for integration, we assume that the values of $\varepsilon$ for each cumulative shock are equal. But the model can handle different $\varepsilon$ for different stages of the crack process.

\subsection{Results and analysis}

The Monte Carlo simulation over a time horizon of $t_{\max }=80$ years is run $N_{\max }=10^{6}$ times. The results are collected and analyzed in the following sections.

\subsubsection{Results of state probabilities}

The estimated state probabilitieswithout,and with random shocksthroughout the time horizon are shown in Figs. 5, and 6, respectively.

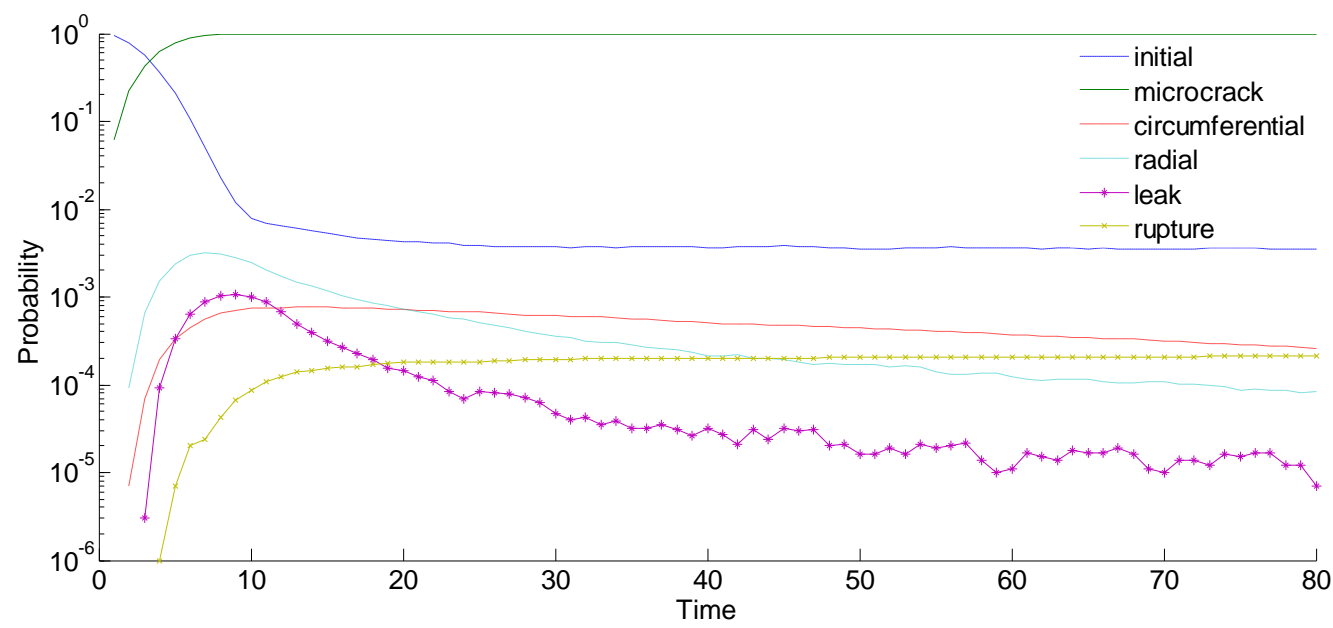


Fig. 5.State probabilities obtained without random shocks.

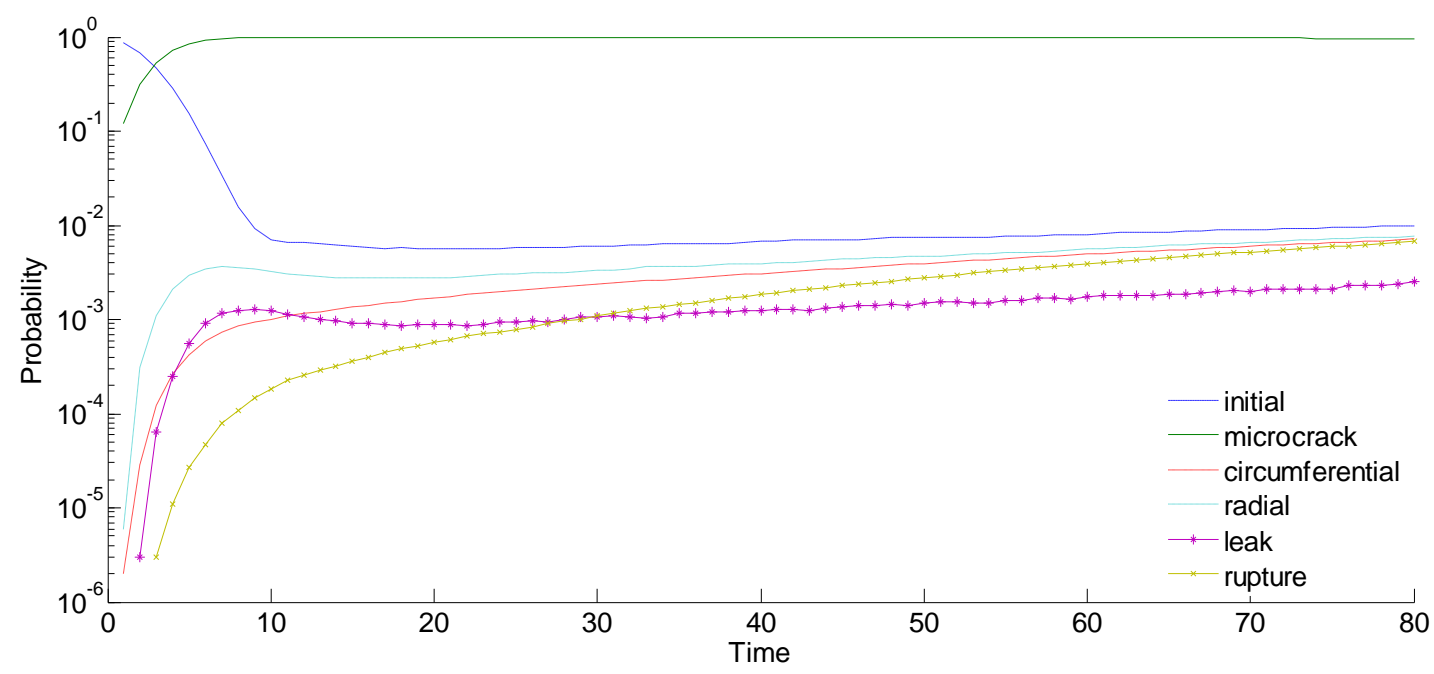

Fig.6.State probabilities obtained with random shocks.

Comparing the above two figures, it can be observed that as expected the random shocks drive the component to higher degradation statesthan the micro-crack state.The numerical comparisons on the state probabilitieswith/without random shocks at year 80 are reported in Table II.It is seen that, except for the micro-crack state probability, all the other state probabilities at year 80 have increased due to the random shocks, with the increase inleak probability being the most significant.

Table II

Comparison of state probabilities with/without random shocks

(at year 80)

\begin{tabular}{|c|c|c|c|}
\hline State & $\begin{array}{c}\text { Probability without } \\
\text { random shocks }\end{array}$ & $\begin{array}{c}\text { Probability with } \\
\text { random shocks }\end{array}$ & $\begin{array}{c}\text { Relative } \\
\text { difference }\end{array}$ \\
\hline Initial & $3.52 \mathrm{e}-3$ & $9.82 \mathrm{e}-3$ & $180.00 \%$ \\
\hline Micro-crack & 0.9959 & 0.9661 & $-2.99 \%$ \\
\hline Circumferential crack & $3.05 \mathrm{e}-4$ & $7.28 \mathrm{e}-3$ & $2286.89 \%$ \\
\hline Radial crack & $1.00 \mathrm{e}-4$ & $7.75 \mathrm{e}-3$ & $7650.00 \%$ \\
\hline Leak & $1.30 \mathrm{e}-5$ & $2.59 \mathrm{e}-3$ & $19823.08 \%$ \\
\hline Rupture state & $2.06 \mathrm{e}-4$ & $7.00 \mathrm{e}-3$ & $3298.06 \%$ \\
\hline
\end{tabular}


The fact that the probability of the initial state (compared with no random shocks) at 80 years has increased is attributed to the maintenance tasks. All the maintenance tasks lead the component to the initial state, and the repair rates from radial macro-crack state, circumferential macro-crack state, and leak state are higher than that from the micro-crack state. The shocks generally increase the component degradation speed, i.e. render the component step to further degradation states (other than micro-crack state) faster than the case without shocks. The transitions to initial state occur more frequentlyfrom further degradation states (other than from the micro-crack state) due to their higher maintenance rates. In summary, this phenomenon is due to the combined effects of shocks.

\subsubsection{Results of component reliability}

The estimated component reliabilitieswith and without random shocks throughout the time horizon are shown in Fig. 7.At year 80, the estimated component reliability with random shocks is 0.9930 ,with sample varianceequal to 6.95e-9.Compared with thecase without random shocks(reliability equals to 0.9998, with sample variance2.00e-10), thecomponent reliabilityhas decreased by $0.68 \%$.

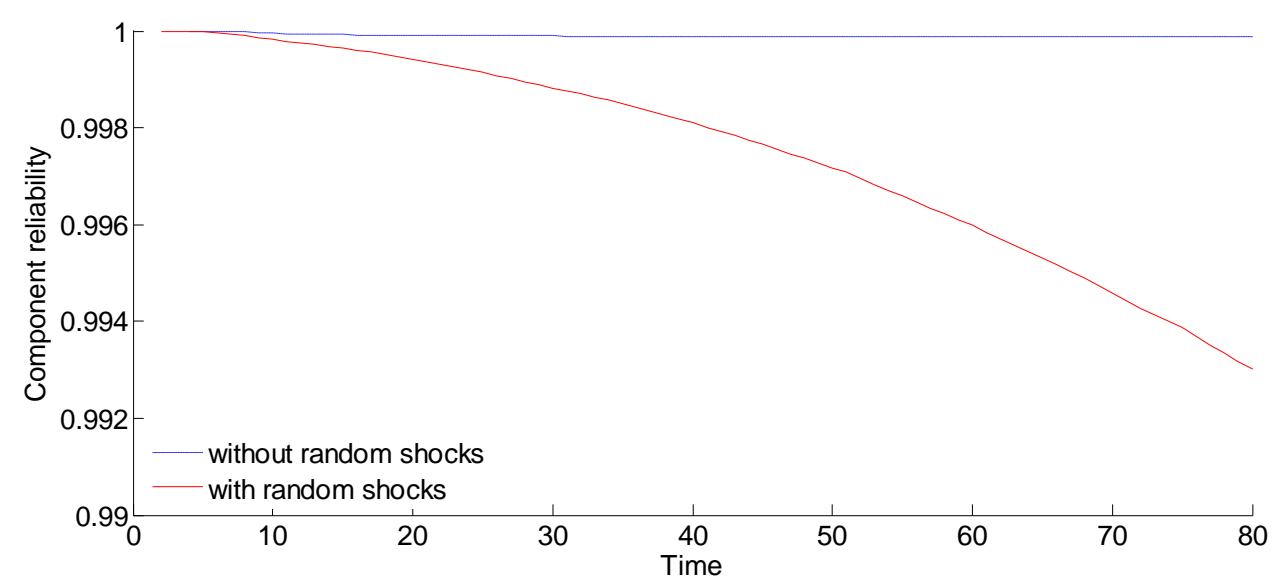

Fig.7.Component reliability estimation with/without random shocks.

\subsubsection{Analysisofthe extreme shocks}


Table IIIpresents the frequenciesof differentnumbers of random shocks that occurredper simulation trial.The most likely number is around 5, which is consistent with our assumption on the value of the occurrence rate $\left(\mu=1 / 15 y^{-1}\right)$ of random shocks.

\section{Table III}

Frequencyof the number of random shocks occurred per trial (mission time $t=80$ years)

\begin{tabular}{|c|c|c|c|c|c|c|c|c|c|c|c|}
\hline $\begin{array}{c}\text { Nb of random } \\
\text { shocks/trial }\end{array}$ & 0 & 1 & 2 & 3 & 4 & 5 & 6 & 7 & 8 & 9 & $>9$ \\
\hline Percentage (\%) & 0.63 & 3.14 & 8.00 & 13.55 & 17.15 & 17.56 & 14.91 & 10.83 & 6.87 & 3.90 & 3.45 \\
\hline
\end{tabular}

In total, 6973 trials ended in failure, among which 4531 trials $(64.98 \%)$ are caused by extreme shocks. Table IVreportsthe number of trials ending with extreme shocks,fordifferentnumbers of cumulative shocks occurringper trial.

Table IV

Number of trials that ended with extreme shocksfor different numbers of cumulative shocks (mission time $t=80$ years)

\begin{tabular}{|c|c|c|}
\hline $\begin{array}{c}\text { Nb of cumulative } \\
\text { shocks per trial }\end{array}$ & Nb of trials & $\begin{array}{c}\text { Nb of trials ending } \\
\text { with extreme shock }\end{array}$ \\
\hline 0 & 6345 & 0 \\
\hline 1 & 31739 & 367 \\
\hline 2 & 80292 & 633 \\
\hline 3 & 135676 & 812 \\
\hline 4 & 171526 & 809 \\
\hline 5 & 175569 & 743 \\
\hline 6 & 148844 & 500 \\
\hline 7 & 108101 & 332 \\
\hline 8 & 68579 & 172 \\
\hline 9 & 38964 & 90 \\
\hline 10 & 19569 & 43 \\
\hline 11 & 8998 & 19 \\
\hline$>11$ & 5798 & 11 \\
\hline
\end{tabular}


The influence of the number of cumulative shocks that occurredper trialon the probability of the next random shock being extreme is shown in Fig. 8.As expected, thelargerthe number of cumulative shocks the higher the probability of extreme shock.

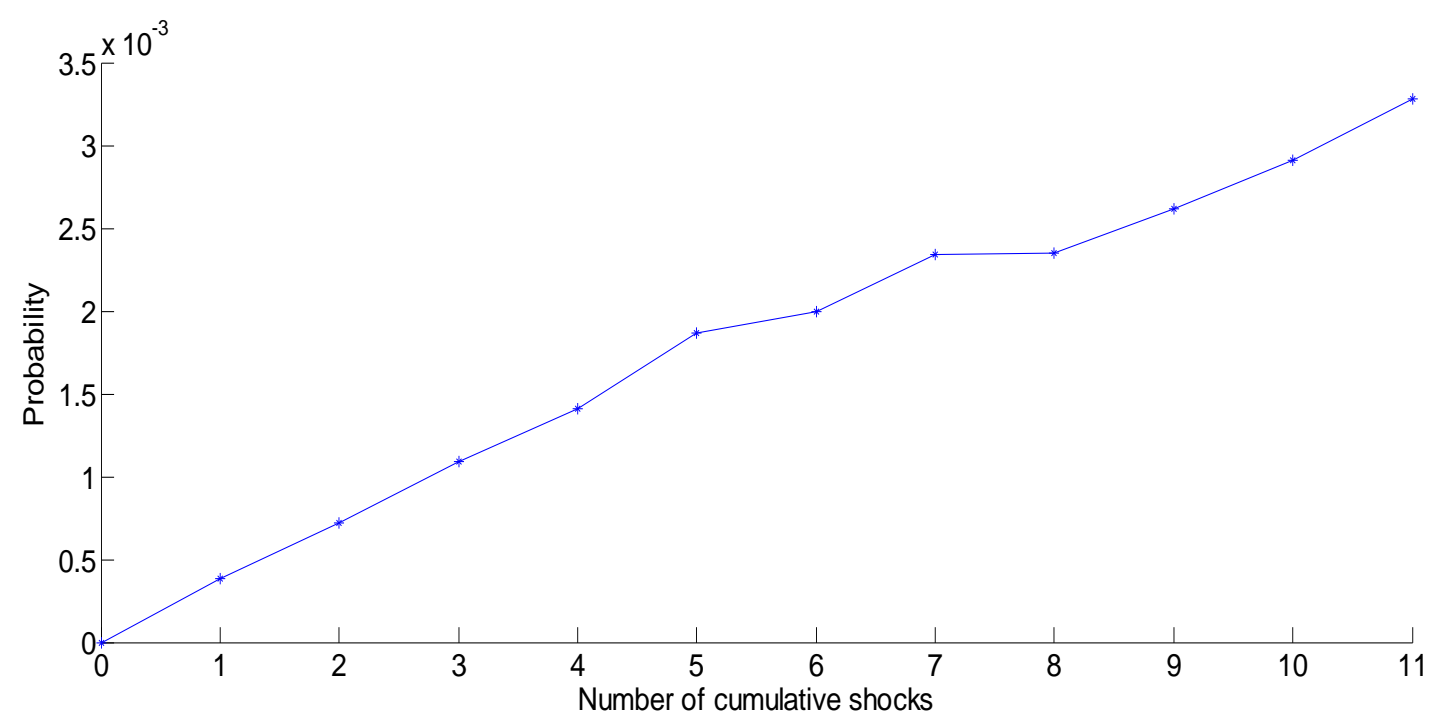

Fig.8.The probability of the next random shock being extremeas a function of the number of cumulative shocks occurred per trial.

The influence of the degradation state on the probability of the next random shock being extreme is shown in Fig. 9.As expected, thelikelihood of extreme shocksis higher whenthe component degradation state is closer to the failure state.

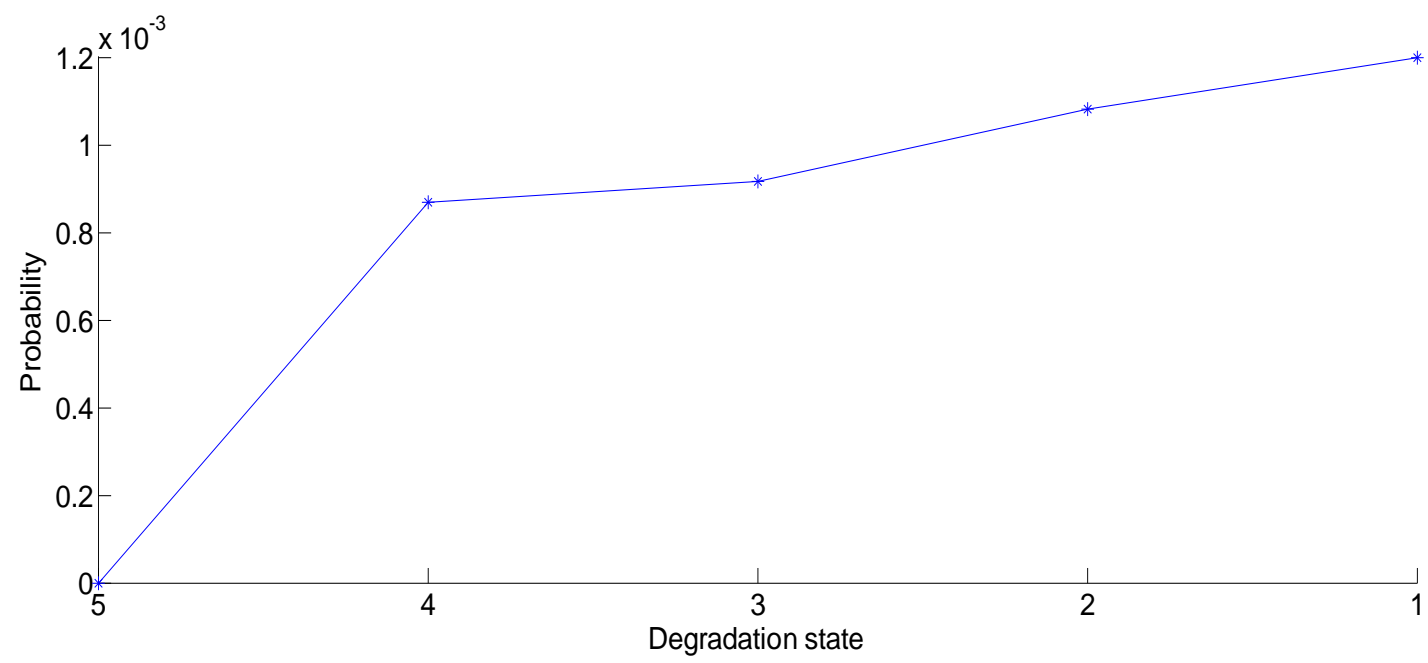


Fig. 9.The probability of the next random shock being extreme as a function of the degradation state of the component.

\subsubsection{Influence of cumulative shocks on degradation}

To characterize the influence of cumulative shocks on the degradation processes, we set to $O$ the probability of a random shock being extreme, so that all random shocks will be cumulative. The estimated state probabilities are shown in Fig. 10.

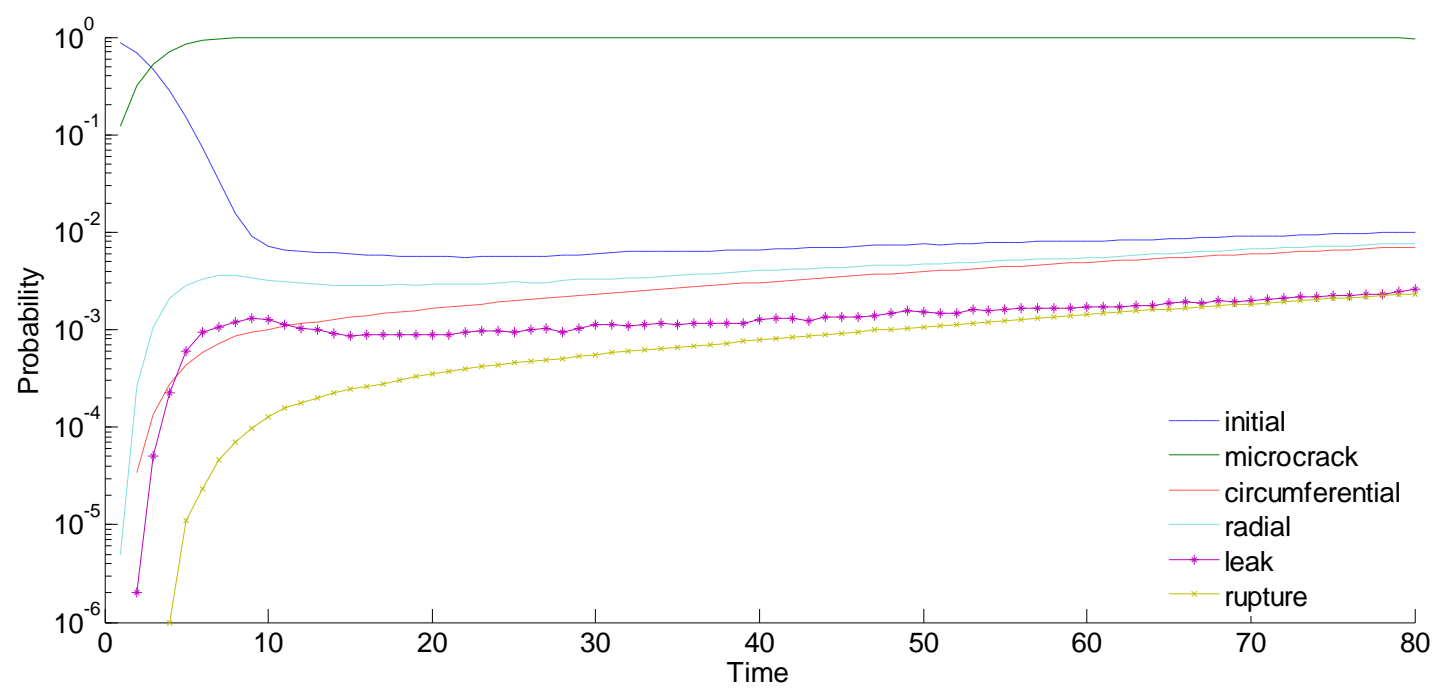

Fig.10.State probabilities obtained with cumulative shocks only.

The state probabilities with cumulative shocks exhibit similar patterns as those in Fig. 6 ;only the rupture state probability has decreased due to the lack of extreme shocks. The numerical comparisons on the state probabilities without random shocks and with cumulative shocks at year 80 are reported in Table V.

Table V

Comparison of state probabilities without random shocks and with cumulative shocks

(at year 80)

\begin{tabular}{|c|c|c|c|}
\hline State & $\begin{array}{c}\text { Probability without } \\
\text { random shocks }\end{array}$ & $\begin{array}{c}\text { Probability with } \\
\text { cumulative shocks }\end{array}$ & Relative difference \\
\hline Initial & $3.52 \mathrm{e}-3$ & $9.94 \mathrm{e}-3$ & $184.11 \%$ \\
\hline
\end{tabular}




\begin{tabular}{|c|l|l|c|}
\hline Micro-crack & 0.9959 & 0.9704 & $-2.56 \%$ \\
\hline Circumferential crack & $3.05 \mathrm{e}-4$ & $7.05 \mathrm{e}-3$ & $2210.16 \%$ \\
\hline Radial crack & $1.00 \mathrm{e}-4$ & $7.52 \mathrm{e}-3$ & $7419.00 \%$ \\
\hline Leak & $1.30 \mathrm{e}-5$ & $2.76 \mathrm{e}-3$ & $21161.54 \%$ \\
\hline Rupture & $2.06 \mathrm{e}-4$ & $2.70 \mathrm{e}-3$ & $1212.62 \%$ \\
\hline
\end{tabular}

As for the case with random shocks, cumulative shocks have a similar influenceon the state probabilities. In Fig. 11, we compare the estimated component reliabilitywith cumulative shockswiththe other two estimated probabilities of Fig. 7.At year 80, the estimated component reliability with cumulative shocks is 0.9973 ,andthe sample variance equals 2.69e-9. Considering cumulative shocks only, thecomponent reliability has decreased by $0.26 \%$.

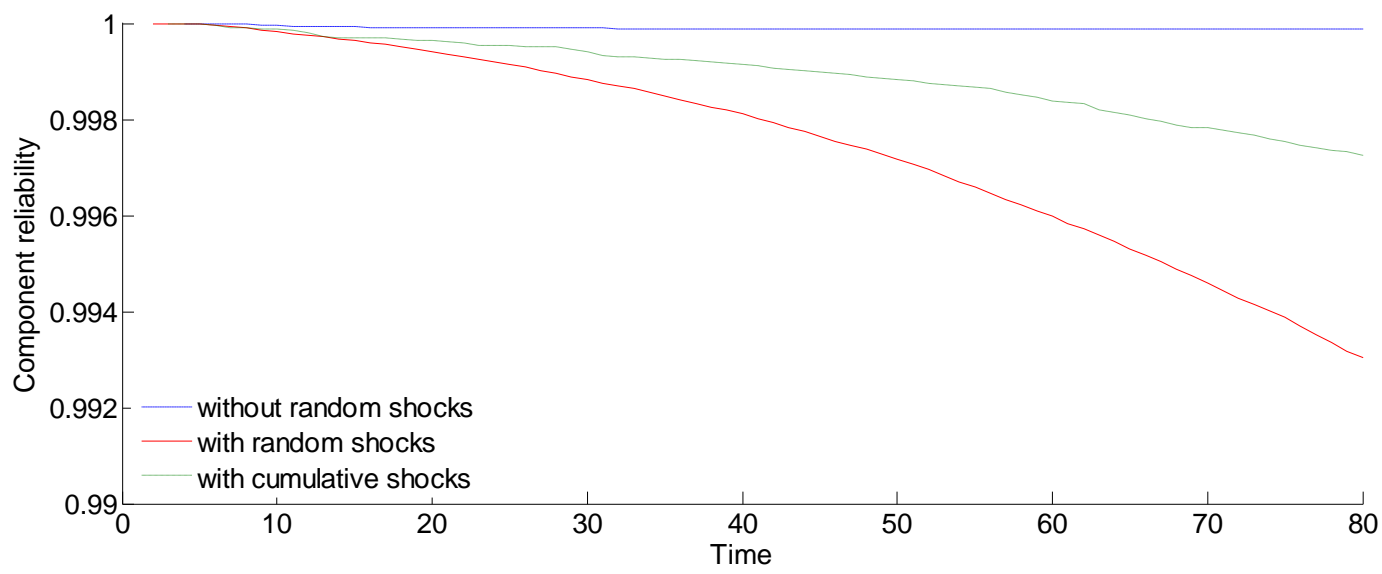

Fig.11.Component reliability with/without random shocks, and with only cumulative shocks.

\subsection{Sensitivity analysis}

With the model specificationsof Section 6.1, two important parametersare: the constant $\delta$ in $p_{\mathrm{i}, \mathrm{m}}\left(\tau_{\mathrm{i}, \mathrm{m}}^{\prime}\right)$ and the relative increment $\sin \lambda_{i, j}^{(m)}\left(\tau_{i, m}^{\prime}, \boldsymbol{\theta}\right)$. To analyze the sensitivity of the component reliabilityestimatesto these two parameters, we take values of $\delta$ within the range $[0.0001,0.0002]$, and $\varepsilon$ within the range $[0.2,0.4]$.

Fig. 12 shows the estimated component reliabilitieswith different combinations of 
the two parameters.In general, the component reliability decreases when any of theparameters increases.In fact,a higher $\delta$ in $p_{\mathrm{i}, \mathrm{m}}\left(\tau_{\mathrm{i}, \mathrm{m}}^{\prime}\right)$ leads to a higher probability ofthe random shock being extreme, which is more critical to the component,anda higher relative increment $\varepsilon$ in $\lambda_{i, j}^{(m)}\left(\tau_{i, m}^{\prime}, \boldsymbol{\theta}\right)$ results in larger degradation transition rates. We can also see from the figure that,in this situation, when the same percentage of variation applies to the two parameters, $\varepsilon$ is more influential than $\delta$ on the component reliability. The corresponding variances of the estimated component reliabilitycomputedusing (19) are shown in Fig. 13,where it is seen that the high reliabilityestimates have low variance levels.

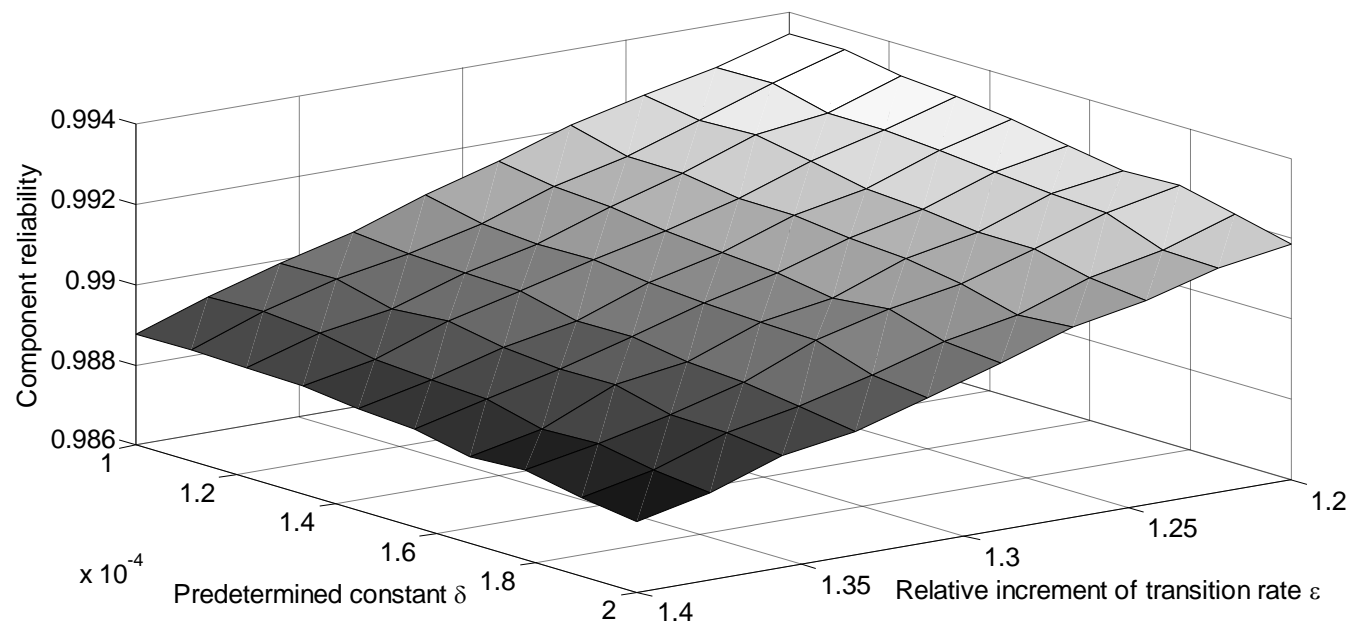

Fig. 12.Component reliability estimateas a function of $\varepsilon$ and $\delta$ (at year 80). 


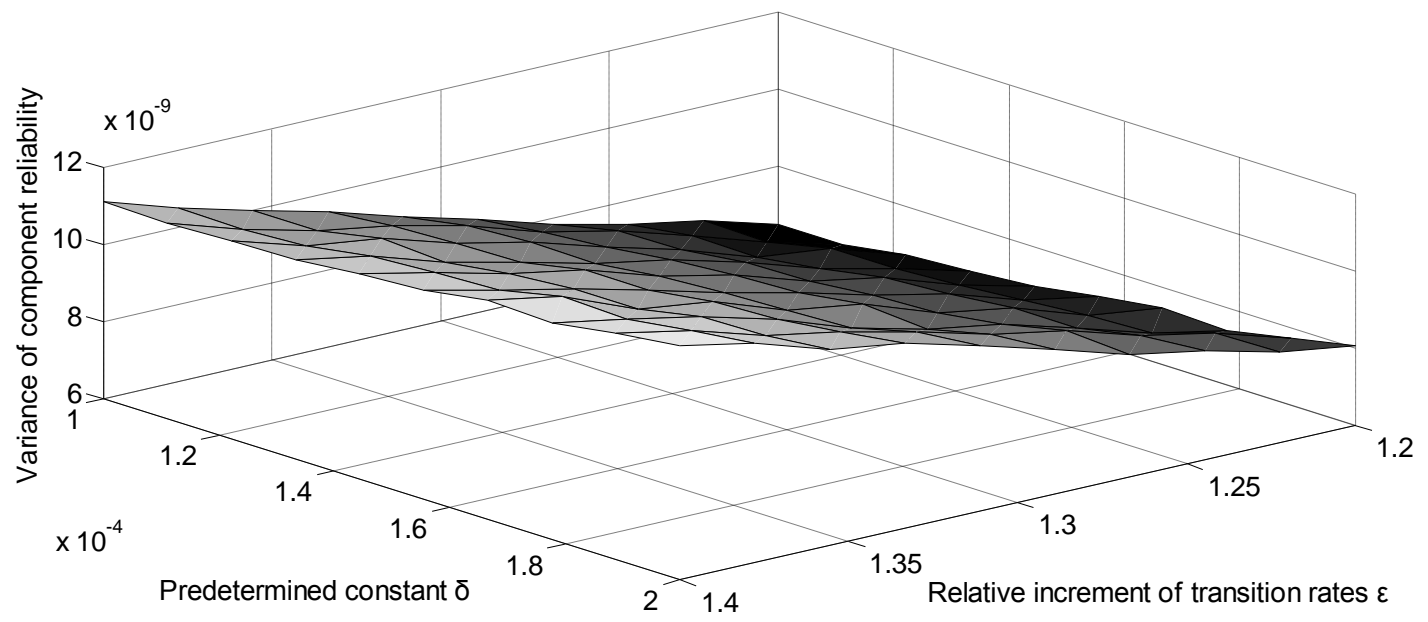

Fig. 13. Variance of component reliability estimate as a function of $\varepsilon$ and $\delta$ (at year 80).

\section{CONCLUSIONS}

An original, general model of a degradation process dependent on random shocks has been proposed and integrated into a MSPM framework with semi-Markov processes, which also considers two types of random shocks: extreme, and cumulative. General dependences between the degradation and the effects of shocks can be considered.

A literature case study has been illustrated to show the effectiveness and modeling capabilities of the proposal, and a crude sensitivity analysis has been applied to a pair of characteristic parameters newly introduced.The significance of the findings in the case study considered isthat our extended model is able to characterize the influences of different types of random shocks onto the component state probabilities and the reliability estimates.

\section{REFERENCES}

[1] W. Li and H. Pham, "Reliability modeling of multi-state degraded systems with multi-competing failures and random shocks," Reliability, IEEE Transactions on, vol. 54, pp. 297-303, 2005.

[2] Z. Wang, H.-Z. Huang, Y. Li, and N.-C. Xiao, "An approach to reliability assessment under degradation and shock process," Reliability, IEEE Transactions on, vol. 60, pp. 852-863, 2011. 
[3] N. Gebraeel, A. Elwany, and J. Pan, "Residual life predictions in the absence of prior degradation knowledge," Reliability, IEEE Transactions on, vol. 58, pp. 106-117, 2009.

[4] J. Lawless and M. Crowder, "Covariates and random effects in a gamma process model with application to degradation and failure," Lifetime Data Analysis, vol. 10 , pp. 213-227, 2004.

[5] C. Guo, W. Wang, B. Guo, and X. Si, "A Maintenance optimization model for mission-oriented systems based on wiener degradation," Reliability Engineering \& System Safety, vol. 111, pp. 183-194, 2013.

[6] A. Lisnianski and G. Levitin, Multi-state system reliability: assessment, optimization and applications vol. 6: World Scientific Publishing Company, 2003.

[7] M. Giorgio, M. Guida, and G. Pulcini, "An age-and state-dependent Markov model for degradation processes," IIE Transactions, vol. 43, pp. 621-632, 2011.

[8] M. J. Kim and V. Makis, "Optimal maintenance policy for a multi-state deteriorating system with two types of failures under general repair," Computers \& Industrial Engineering, vol. 57, pp. 298-303, 2009.

[9] Y.-F. Li, E. Zio, and Y.-H. Lin, "A Multistate Physics Model of Component Degradation Based on Stochastic Petri Nets and Simulation," Reliability, IEEE Transactions on, vol. 61, pp. 921-931, 2012.

[10]G. Yang, Life cycle reliability engineering: Wiley, 2007.

[11]M.-W. Lu and R. J. Rudy, "Laboratory reliability demonstration test considerations," Reliability, IEEE Transactions on, vol. 50, pp. 12-16, 2001.

[12]J. I. Park and S. J. Bae, "Direct prediction methods on lifetime distribution of organic light-emitting diodes from accelerated degradation tests," Reliability, IEEE Transactions on, vol. 59, pp. 74-90, 2010.

[13]M. Daigle and K. Goebel, "A model-based prognostics approach applied to pneumatic valves," International Journal of Prognostics and Health Management, vol. 2, pp. 1-16, 2011.

[14]M. Daigle and K. Goebel, "Multiple damage progression paths in model-based prognostics," in Aerospace Conference, 2011 IEEE, March 5-12,2011, pp. 1-10.

[15]E. E. Kostandyan and J. D. Sørensen, "Physics of failure as a basis for solder elements reliability assessment in wind turbines," Reliability Engineering \& System Safety, 2012.

[16]S. D. Unwin, P. P. Lowry, R. F. Layton, P. G. Heasler, and M. B. Toloczko, "Multi-state physics models of aging passive components in probabilistic risk assessment," in International Topical Meeting on Probabilistic Safety Assessment and Analysis (PSA 2011), March 13-17, 2011, Wilmington, North Carolina, vol. 1 , pp. 161-172.

[17]K. N. Fleming, S. D. Unwin, D. Kelly, P. P. Lowry, M. B. Toloczko, R. F. Layton, et al., "Treatment of Passive Component Reliability in Risk-Informed Safety Margin Characterization," Idaho National Laboratory, INL/EXT-10-20013, Idaho Falls, Idaho2010, pp. 1-210.

[18]T. Nakagawa, Shock and damage models in reliability theory: Springer, 2007.

[19]B. O. Y.Lydell, "Pipe failure probability - the Thomas paper revisited," Reliability Engineering \& System Safety, vol. 68, no 3, p. 207-217, 2000.

[20]J.Salonen, P. Auerkari,O.Lehtinen, andM.Pihkakoski,"Experience on in-service damage in power plant components," Engineering Failure Analysis, vol. 14, no 6, pp. 970-977, 2007.

[21]J.-M. Bai, Z.-H. Li, and X.-B. Kong, "Generalized shock models based on a cluster point process," Reliability, IEEE Transactions on, vol. 55, pp. 542-550, 2006.

[22]Y. Wang and H. Pham, "Modeling the dependent competing risks with multiple degradation processes and random shock using time-varying copulas," Reliability, IEEE Transactions on, vol. 61, pp. 13-22, 2012.

[23]J. Esary and A. Marshall, "Shock models and wear processes," The annals of probability, pp. 627-649, 1973.

[24]A. Gut, "Extreme shock models," Extremes, vol. 2, pp. 295-307, 1999.

[25] K. K. Anderson, "Limit theorems for general shock models with infinite mean intershock times," Journal of applied probability, pp. 449-456, 1987.

[26]G. Agrafiotis and M. Tsoukalas, "On excess-time correlated cumulative processes," Journal of the Operational Research Society, pp. 1269-1280, 1995. 
[27]T. Nakagawa and M. Kijima, "Replacement policies for a cumulative damage model with minimal repair at failure," Reliability, IEEE Transactions on, vol. 38, pp. 581-584, 1989.

[28]Z. S. Ye, L. C. Tang, and H. Y. Xu, "A distribution-based systems reliability model under extreme shocks and natural degradation," Reliability, IEEE Transactions on, vol. 60, pp. 246-256, 2011.

[29]J. Fan, S. Ghurye, and R. A. Levine, "Multicomponent lifetime distributions in the presence of ageing," Journal of applied probability, vol. 37, pp. 521-533, 2000.

[30]G.-A. Klutke and Y. Yang, "The availability of inspected systems subject to shocks and graceful degradation," Reliability, IEEE Transactions on, vol. 51, pp. $371-374,2002$.

[31]M. Wortman, G.-A. Klutke, and H. Ayhan, "A maintenance strategy for systems subjected to deterioration governed by random shocks," Reliability, IEEE Transactions on, vol. 43, pp. 439-445, 1994.

[32] G.Becker, L.Camarinopoulos, and D.Kabranis, "Dynamic reliability under random shocks," Reliability Engineering \& System Safety, vol. 77, no 3, pp. 239-251, 2002.

[33]W.S.Yang, D.E.Lim, and K.C.Chae,"Maintenance of multi-state production systems deteriorated by random shocks and production," Journal of Systems Science and Systems Engineering, vol. 20,pp. 110-118,2011.

[34]A. V. Huzurbazar and B. Williams, "Flowgraph models for complex multistate system reliability," Modern statistical and mathematical methods in reliability, vol. 10, pp. 247-262, 2005.

[35]Z. Schuss, Theory and applications of stochastic processes: Springer, 2010.

[36]D. T. Gillespie, "Monte Carlo simulation of random walks with residence time dependent transition probability rates," Journal of Computational Physics, vol. 28, pp. 395-407, 1978.

[37]E. Rachelson, G. Quesnel, F. Garcia, and P. Fabiani, "A simulation-based approach for solving generalized semi-markov decision processes," in European Conference on Artificial Intelligence, 2008.

[38]H. A. Chan and P. J. Englert, Accelerated stress testing handbook: JW, 2001.

[39]E. Lewis and F. Böhm, "Monte Carlo simulation of Markov unreliability models," Nuclear Engineering and Design, vol. 77, pp. 49-62, 1984.

Yan-Hui Linhas been a doctoral studentat Chair on Systems Science and the

Energetic Challenge, European Foundation for New Energy - EDF, CentraleSupélec,

France since August 2012. His research interests are in reliability anddegradation

modeling,Monte Carlo simulation, and optimization under uncertainty.

Yan-Fu Li (M' 11)is an Assistant Professor at Chair on Systems Science and the

Energetic Challenge, European Foundation for New Energy - EDF, CentraleSupélec,

France. Dr. Li completed his PhD research in 2009 at National University of

Singapore, and went to the University of Tennessee as a research associate in 2010.

His research interests include reliability modeling and optimization, uncertainty modeling and analysis, and evolutionary computing. He is the author of more than 20international journals including IEEE Transactions on Reliability, Reliability 
Engineering\& Systems Safety, and IEEE Transactions on Power Systems. He is an invited reviewerof over 20 international journals. He is a member of the IEEE.

Enrico Zio(M' 06 - SM' 09) received the Ph.D. degree in nuclear engineering from Politecnico di Milano, and MIT in 1995, and 1998, respectively. He is currently Director of the Chair on Systems Science and the Energetic Challenge, European Foundation for New Energy - EDF, CentraleSupélec, France, and full professor at Politecnico di Milano. His research focuses on the characterization and modeling of the failure-repair-maintenance behavior of components, and complex systems; and their reliability, maintainability, prognostics, safety, vulnerability, and security; Monte Carlo simulation methods; soft computing techniques; and optimization heuristics. 